\title{
Analysis of Test Items used in an Achievement Test in Physics at Secondary Level
}

\author{
Ph.D. Scholar (Education), Shahzad Ahmad \\ Federal College of Education, H-9, Islamabad \\ Research Associate, Sadia Jamil \\ Federal College of Education, H-9, Islamabad
}

\begin{abstract}
Aim of present study was the analysis of test items constructed in an achievement test in the subject of physics for class IX. It was used to study the difficulty level, discrimination power and distracter analysis of each test item. The achievement test was comprised of 40 multiple choice questions. Test was administered by researcher on a sample of 250 students from Islamabad Model Schools in Sector G-9. Findings of the study showed that most of the test items fall in acceptable range of difficulty index and discrimination power. In keeping view, the findings of the study, researcher comes to know that most of the test items prove to be satisfactory regarding difficulty index and discriminating power. However, ten out of forty test items were discarded due to high or very low level of difficulty and poor discrimination power. This work is equally significant for the researchers and for the subject teachers in preparing achievement tests in order to assess performance of students with optimum level of difficulty index and discriminating power.
\end{abstract}

Keywords: Item Difficulty; Discrimination Index; Distracter Analysis and Reliability.

DOI: $10.7176 / \mathrm{JEP} / 10-10-10$

Publication date: April $30^{\text {th }} 2019$

\subsection{Introduction}

The achievement test is considered as a process to monitor and evaluate teaching learning activities. It is helpful for the improvement of instructional process by providing feedback to both the students as well as the teachers. Achievement test is an instrument for teachers in order to determine their students' performance in particular situation. It is mainly focused in evaluating someone's performance in a specific subject at the end of instructional period. According to Best and Khan (2006), "Achievement tests attempt to measure what an individual has learned - his or her present level of performance".

Item analysis is a statistical technique which is used to ascertain the usefulness of test items in preparing achievement tests. In order to develop quality assessment test and precisely useful multiple-choice items, item analysis plays an important role both in contributing to the objectivity of the test and to highlight the areas where students are conceptually weak.

According to Brown and Frederick (1971), Item analysis has two main purposes: Firstly, to identify imperfect test items and secondly, to highlight particular content areas which learners have or have not fully mastered. The main function of item analysis procedure is to measures usefulness of each test items in term of its difficulty level and the capacity to differentiate between high and low achievers of particular test. In nutshell, item analysis helps in selecting and keeping the best test items for final draft of the test and discarding poor test items. There is also scope for reviewing and modifying the ill constructed test items.

In general, once test items have been prepared, the worth of such items can be assessed using number of procedures representative of item analysis a) the difficulty level of the test items b) the capacity of the individual test item to differentiate, and c) the distracter analysis. Difficulty concerns with how many number of persons recommending the answer correctly. Discrimination can be observed by making comparison of persons getting a particular item correct with the total test score. Finally, the distracter analysis concerns with the quality of distracters.

\subsection{Purpose of the study}

The purpose of the study was to determine the items difficulty level, discrimination power and distracters analysis of the test items used in an achievement test in physics at secondary level.

\subsection{Objectives of the study}

The objectives of the study are as follow:

1. To find out the difficulty level of individual test item.

2. To find out the discrimination power of individual test item.

3. To study the distracters analysis of test items.

4. To find out the test reliability of the test items. 


\subsection{Significance of the Study}

Successes of any education system rely solely on the well-established system of examination. Examination on one hand play the role for promoting students to next grade and on the other hand provides scope for assessment of curriculum, program and performance of teachers. The significance of the study may be understood as

- It enables subject teacher to know about the too easy and too difficult test items (Items difficulty).

- It enables him to differentiate between high achievers and low achievers (Discrimination power).

- It enables him to construct useful distracters (Distracters analysis).

- It also provides scope for checking whether the test under consideration is reliable or unreliable (Test reliability).

\subsection{Instrument of the Study}

The instrument of the study was comprised of 40 test items for data collection. Initially test was consisting of 60 test items from unit on motion and rest in physics for class IX by Punjab text book board, Lahore. The test was developed by researcher himself and approved by experts in the subject of physics at secondary level. All experts ensured that various levels of Bloom's Taxonomy have got due weightage. Test items which found ambiguous, providing clues and of language issues were discarded. All necessary instructions were provided to the participants to ensure reliability.

\subsection{Population of the study}

The population of the study comprised of all students of class $9^{\text {th }}$ in Islamabad Model Schools in G-9 sector, Islamabad.

\subsection{Sample of the Study}

Simple random sampling technique was used to obtain a sample of 250 students at secondary level. Sample comprised of the students of both genders. Sample of the study in detail shown in figure 1.

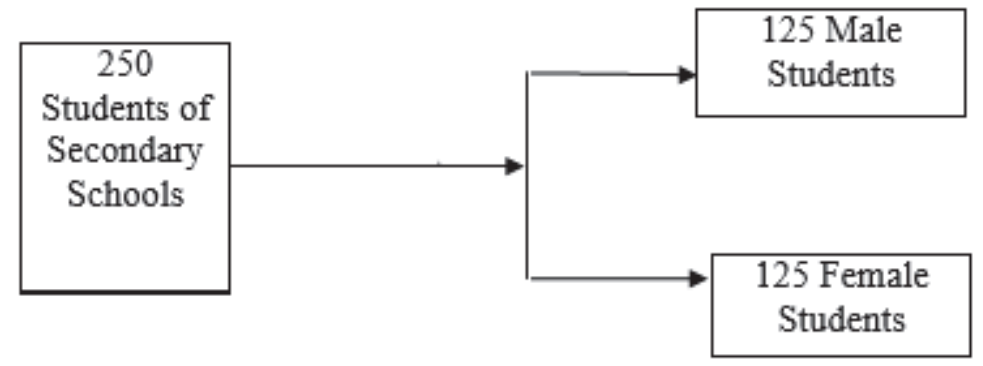

Figure 1: Sample in detail.

\subsection{Data Collection}

Achievement test in physics was administered by the researcher himself to the sample of 250 students. Initially students were informed about the particular unit for achievement test and concerning directions for its administration.

\subsection{Data Analysis}

Student's scores on test items were arranged by using MS-Excel in descending order. In order to start the item analysis top 30\% scorers and bottom 30\% scorers of the entire sample were selected. Upper and lower group of students each comprised of 75 students was used. Nunnally (1972) suggested 25\% while SPSS (1999) uses the highest and lowest one third (33\%).

\subsubsection{Item Difficulty (F)}

It deals with how difficult is the test item. It is indicated by the percentage of the pupils who got the item right. It is recommended that test item would be neither too easy nor too difficult. It involves following basic steps:

1) Arrange the papers in order from the highest to the lowest scores (say 250 papers).

2) Select $30 \%$ papers with the highest scores (high achievers) - 75 papers.

3) Select $30 \%$ papers with the lowest scores (low achievers) - 75 papers.

4) $40 \%$ papers in the middle (100 papers) would not be taken in account.

5) Calculate the correct responses of high achievers and low achievers on each item.

6) Apply the formula and calculate F (Facility Index)

$\mathbf{F}=\mathbf{N R} / \mathbf{N T} \quad$ Where

$\mathrm{NR}=$ Number of students who got the item right. 
$\mathrm{NT}=$ Total number of students.

7) $\mathrm{F}$ is acceptable when it ranges from 0.30 to 0.90.

8) Value more than 0.90 indicates that item is very easy.

9) Value less than 0.30 indicates that item is very difficult.

Table 1:

High Achievers $=75$, Total papers $=250$, Low Achievers $=75$

\begin{tabular}{rrrrrrr}
\hline & N & a & b & c & d & Omit \\
\hline High Achievers & 75 & 13 & 53 & 03 & 06 & 0 \\
Low Achievers & 75 & 12 & 43 & 07 & 13 & 0 \\
\hline
\end{tabular}

"b" is the correct answer $(b=96)$.

$$
\begin{aligned}
\mathrm{F} & =\mathrm{NR} / \mathrm{NT} \\
& =96 / 150 \\
& =0.64
\end{aligned}
$$

Table 2:

Evaluation of Item Difficulty for Item Analysis.

\begin{tabular}{ll}
\hline Item Difficulty Index & Item Evaluation \\
\hline Above 0.90 & Very easy item \\
Between 0.20 and 0.90 & Ideal item \\
Below 0.20 & Very difficult item \\
\hline \multicolumn{2}{c}{ Source: Instructional Assessment Resources (IAR 2011). }
\end{tabular}

\subsubsection{Discrimination Power (D)}

It refers to the degree to which test item discriminates between pupils with high and low achievement. One purpose of testing is to discriminate between high and low achievers. It involves following basic steps:

1) Arrange the papers in order from the highest to the lowest scores (say 250 papers).

2) Select 30\% papers with the highest scores (high achievers) - 75 papers.

3) Select $30 \%$ papers with the lowest scores (low achievers) - 75 papers.

4) $40 \%$ papers in the middle (100 papers) would not be taken in account.

5) Calculate the correct responses of high achievers and low achievers on each item.

6) Apply the formula and calculate D

\section{$\mathrm{D}=\mathrm{NH}-\mathrm{NL} / \mathbf{n}$}

Where

$\mathrm{n}=$ Number of high or low achievers.

$\mathrm{NH}=$ Number of high achievers who got the item right.

$\mathrm{NL}=$ Number of low achievers who got the item right.

7) $\mathrm{D}$ is acceptable when it ranges from 0.30 to 1.0 .

8) Value more than 0.40 indicates $100 \%$ discrimination.

9) Value less than 0.30 indicates incapability of the item to discriminate.

Table 3:

High Achievers $=75$, Total papers $=250$, Low Achievers $=75$

\begin{tabular}{lcccccc}
\hline & N & a & b & c & D & Omit \\
\hline High Achievers & 75 & 09 & 56 & 09 & 01 & 0 \\
Low Achievers & 75 & 24 & 22 & 25 & 04 & 0 \\
\hline
\end{tabular}

" $b$ " is the correct answer $(b=78)$.

$\mathrm{D}=\mathrm{NH}-\mathrm{NL} / \mathrm{n}$

$=56-22 / 75$

$=0.45$

Table 4:

Evaluation of Discrimination Indexes for Item Analysis.

\begin{tabular}{ll}
\hline Index of Discrimination & Item Evaluation \\
\hline 0.40 and above & Very good item; accept \\
0.30 to 0.39 & Reasonably good but subject to improvement \\
0.20 to 0.29 & Marginal item usually need and subject to improvement \\
Below 0.19 & Poor item to be rejected or improved by revision \\
\hline
\end{tabular}

Source: Ebel (1972) in Ovwigho (2013).

\subsubsection{Distracters Analysis}

The last but not least stage in item analysis procedure is to assess the quality of distracters for each test items. These are incorrect alternatives alongside correct option in case of multiple choice items. The quality of good distracters is to "distract" examinees which are unaware of the right response. 
Distracter analysis provides the information to instructor to observe that how many numbers of testers in the upper group and bottom group tick out each option on a multiple-choice item. Distracter fails to do its job when it is not selected by examinees at all. In other words, the usefulness of distracter relies solely on its selection by some examinees. Otherwise it is ineffective and must be revised or replaced. When distracter attracts more examinees from the bottom group than the upper group it is negative discrimination. Similarly, when distracter attracts more examinees from upper group than the bottom group it is positive discrimination. Distracters should demonstrate negative discrimination.

Table 5:

High Achievers $=75$, Total papers $=250$, Low Achievers $=75$

\begin{tabular}{ccccccc}
\hline & $\mathrm{N}$ & $\mathrm{a}$ & $\mathrm{B}$ & $\mathrm{C}$ & $\mathrm{d}$ & Omit \\
\hline High Achievers & 75 & 09 & 56 & 09 & 01 & 0 \\
Low Achievers & 75 & 24 & 22 & 25 & 04 & 0 \\
\hline
\end{tabular}

\subsection{Findings and Discussion}

\subsubsection{Item Difficulty}

Table 6:

Includes the item difficulty indices of each test item.

\begin{tabular}{|c|c|c|c|}
\hline Item No. & Item Difficulty & Item No. & Item Difficulty \\
\hline 1 & 0.71 & 21 & 0.36 \\
\hline 2 & 0.74 & 22 & 0.28 \\
\hline 3 & 0.64 & 23 & 0.74 \\
\hline 4 & 0.69 & 24 & 0.67 \\
\hline 5 & 0.24 & 25 & 0.52 \\
\hline 6 & 0.56 & 26 & 0.42 \\
\hline 7 & 0.63 & 27 & 0.58 \\
\hline 8 & 0.66 & 28 & 0.45 \\
\hline 9 & 0.12 & 29 & 0.92 \\
\hline 10 & 0.66 & 30 & 0.67 \\
\hline 11 & 0.76 & 31 & 0.78 \\
\hline 12 & 0.30 & 32 & 0.80 \\
\hline 13 & 0.80 & 33 & 0.90 \\
\hline 14 & 0.40 & 34 & 0.70 \\
\hline 15 & 0.31 & 35 & 0.58 \\
\hline 16 & 0.77 & 36 & 0.70 \\
\hline 17 & 0.49 & 37 & 0.32 \\
\hline 18 & 0.22 & 38 & 0.36 \\
\hline 19 & 0.66 & 39 & 0.58 \\
\hline 20 & 0.16 & 40 & 0.60 \\
\hline
\end{tabular}

In accordance with Instructional Assessment Resources (IAR), numbers of test items were classified in to following three categories of item difficulty as indicated in table 7 .

Table 7:

Items Difficulty Indices of items of the achievement test

\begin{tabular}{ccclc}
\hline S.No. & Items Difficulty & Frequency & \multicolumn{1}{c}{ Items } & Remarks \\
\hline 1 & Above 0.90 & 1 & 29 & Rejected \\
& Between 0.20 & & $1,2,3,4,5,6,7,8,10,11,12,13,14,15,16,17,18,19$, & \\
2 & and 0.90 & 37 & $21,22,23,24,25,26,27,28,30,31,32,33,34,35,36$, & Accepted \\
& Below 0.20 & 02 & 9,20 & Rejected \\
\hline
\end{tabular}

Table 7 shows data related to item difficulty. There are 37 test items with difficulty index ranging from 0.20 to 0.90 . Researcher retained these items in the achievement test. Two items having difficulty index below 0.20 and one items with difficulty index above 0.90 were rejected. 


\subsubsection{Item Discrimination}

Table 8:

Includes the coefficient of item Discrimination of each test item.

\begin{tabular}{|c|c|c|c|}
\hline Item No. & Item Discrimination & Item No. & Item Discrimination \\
\hline 1 & 0.36 & 21 & 0.34 \\
\hline 2 & 0.22 & 22 & 0.09 \\
\hline 3 & 0.13 & 23 & 0.42 \\
\hline 4 & 0.42 & 24 & 0.30 \\
\hline 5 & 0.04 & 25 & 0.45 \\
\hline 6 & 0.45 & 26 & 0.26 \\
\hline 7 & 0.38 & 27 & 0.24 \\
\hline 8 & 0.36 & 28 & 0.29 \\
\hline 9 & 0.08 & 29 & 0.14 \\
\hline 10 & 0.45 & 30 & 0.36 \\
\hline 11 & 0.61 & 31 & 0.33 \\
\hline 12 & 0.16 & 32 & 0.64 \\
\hline 13 & 0.22 & 33 & 0.18 \\
\hline 14 & 0.05 & 34 & 0.38 \\
\hline 15 & 0.12 & 35 & 0.34 \\
\hline 16 & 0.21 & 36 & 0.46 \\
\hline 17 & 0.37 & 37 & 0.28 \\
\hline 18 & 0.24 & 38 & 0.29 \\
\hline 19 & 0.38 & 39 & 0.33 \\
\hline 20 & 0.01 & 40 & 0.48 \\
\hline
\end{tabular}

Table 9 includes the classification of test item into different levels of discrimination regarding discrimination coefficient by Ebel (1972) in Ovwigho (2013).

Table 9:

Items Discrimination Indices of items of the achievement test

\begin{tabular}{|c|c|c|c|c|}
\hline S.No. & Items Difficulty & Frequency & Items & Remarks \\
\hline 1 & $\begin{array}{l}\text { Between } 0.40 \\
\text { and } 0.90\end{array}$ & 08 & $04,06,10,11,25,32,36,40$ & Very Good \\
\hline 2 & $\begin{array}{l}\text { Between } 0.30 \\
\quad \text { and } 0.39\end{array}$ & 12 & $\begin{array}{l}01,07,08,17,19,21,24,30 \\
31,34,35,39 .\end{array}$ & $\begin{array}{l}\text { Reasonably } \\
\text { Good }\end{array}$ \\
\hline 3 & $\begin{array}{l}\text { Between } 0.20 \\
\quad \text { and } 0.29\end{array}$ & 10 & $\begin{array}{l}1,5,6,8,13,14,31,43,57,59 \\
64,69,70,78,83,87,94,100,108, \\
112,114,118\end{array}$ & Marginal \\
\hline 4 & 0.19 and below & 10 & $03,05,09,12,14,15,20,22,29,33$ & Rejected \\
\hline
\end{tabular}

Table 9 shows data related to discrimination index. There are eight test items with discrimination index between 0.40 and 0.90 . Researcher retained these test items in the achievement test without any sort of revision. Tests items having discrimination index between 0.30 and 0.39 were reasonably good and demand very little revision. Test items having discrimination index between 0.20 and 0.29 were marginally good and need revision in term readability and language clarity. Remaining ten test items with discrimination below 0.19 were rejected. 


\subsubsection{Distracters Analysis}

Table: 10

Includes the responses of subjects on each test item.

\begin{tabular}{|c|c|c|c|c|c|c|c|c|c|}
\hline \multirow{3}{*}{ 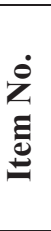 } & \multirow{3}{*}{ 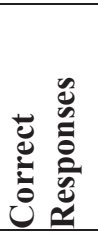 } & \multicolumn{8}{|c|}{ Item Responses } \\
\hline & & \multicolumn{2}{|c|}{$\mathbf{A}$} & \multicolumn{2}{|c|}{ B } & \multicolumn{2}{|c|}{ c } & \multicolumn{2}{|c|}{ D } \\
\hline & & Upper & lower & upper & lower & upper & lower & upper & Lower \\
\hline 1 & B & 00 & 00 & 67 & 40 & 00 & 02 & 08 & 33 \\
\hline 2 & $\mathrm{C}$ & 01 & 01 & 01 & 05 & 64 & 47 & 09 & 13 \\
\hline 3 & B & 13 & 12 & 53 & 43 & 03 & 07 & 06 & 13 \\
\hline 4 & C & 06 & 12 & 00 & 15 & 68 & 36 & 01 & 12 \\
\hline 5 & D & 11 & 15 & 18 & 21 & 26 & 22 & 20 & 17 \\
\hline 6 & $\mathrm{C}$ & 05 & 14 & 20 & 22 & 49 & 35 & 01 & 04 \\
\hline 7 & $\mathrm{C}$ & 02 & 13 & 07 & 16 & 61 & 34 & 05 & 12 \\
\hline 8 & $\mathrm{C}$ & 03 & 10 & 00 & 10 & 64 & 35 & 08 & 20 \\
\hline 9 & B & 36 & 53 & 12 & 06 & 21 & 10 & 06 & 06 \\
\hline 10 & C & 08 & 39 & 01 & 01 & 65 & 35 & 01 & 00 \\
\hline 11 & $\mathrm{C}$ & 05 & 05 & 02 & 14 & 67 & 47 & 01 & 09 \\
\hline 12 & $\mathbf{A}$ & 29 & 17 & 23 & 32 & 17 & 19 & 06 & 06 \\
\hline 13 & $\mathbf{A}$ & 69 & 52 & 01 & 04 & 05 & 12 & 00 & 07 \\
\hline 14 & B & 20 & 17 & 32 & 28 & 13 & 17 & 10 & 13 \\
\hline 15 & $\mathbf{A}$ & 28 & 19 & 14 & 12 & 16 & 15 & 17 & 29 \\
\hline 16 & B & 06 & 16 & 66 & 50 & 00 & 03 & 03 & 06 \\
\hline 17 & B & 22 & 42 & 51 & 23 & 01 & 06 & 01 & 04 \\
\hline 18 & D & 18 & 24 & 11 & 15 & 20 & 28 & 26 & 08 \\
\hline 19 & $\mathrm{C}$ & 02 & 18 & 02 & 13 & 67 & 33 & 04 & 11 \\
\hline 20 & B & 34 & 08 & 13 & 12 & 08 & 09 & 20 & 46 \\
\hline
\end{tabular}

\begin{tabular}{|c|c|c|c|c|c|c|c|c|c|}
\hline \multirow{3}{*}{ 远 } & \multirow{3}{*}{ 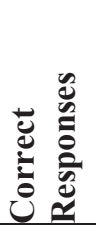 } & \multicolumn{8}{|c|}{ Item Responses } \\
\hline & & \multicolumn{2}{|c|}{$\mathbf{a}$} & \multicolumn{2}{|c|}{ B } & \multicolumn{2}{|c|}{ c } & \multicolumn{2}{|c|}{ D } \\
\hline & & Upper & lower & Upper & Lower & upper & lower & upper & Lower \\
\hline 21 & $\mathrm{C}$ & 17 & 24 & 15 & 32 & 40 & 14 & 03 & 05 \\
\hline 22 & D & 17 & 13 & 08 & 12 & 25 & 32 & 25 & 18 \\
\hline 23 & $\mathbf{C}$ & 01 & 04 & 03 & 21 & 72 & 40 & 00 & 10 \\
\hline 24 & $\mathbf{C}$ & 07 & 17 & 01 & 02 & 62 & 39 & 05 & 17 \\
\hline 25 & B & 09 & 24 & 56 & 22 & 09 & 25 & 01 & 04 \\
\hline 26 & $\mathbf{A}$ & 42 & 22 & 21 & 30 & 07 & 15 & 05 & 08 \\
\hline 27 & B & 12 & 10 & 53 & 35 & 03 & 13 & 07 & 17 \\
\hline 28 & $\mathbf{A}$ & 45 & 23 & 16 & 37 & 09 & 10 & 05 & 05 \\
\hline 29 & D & 00 & 03 & 00 & 04 & 00 & 04 & 75 & 64 \\
\hline 30 & B & 05 & 11 & 64 & 37 & 02 & 14 & 04 & 13 \\
\hline 31 & B & 04 & 21 & 71 & 46 & 00 & 02 & $\mathbf{0 0}$ & 06 \\
\hline 32 & $\mathrm{C}$ & 02 & 22 & 01 & 04 & 72 & 48 & 00 & 01 \\
\hline 33 & D & 00 & 02 & 00 & 05 & 00 & 07 & 75 & 61 \\
\hline 34 & B & $\mathbf{0 7}$ & 22 & 67 & 38 & 01 & 06 & 00 & 09 \\
\hline 35 & $\mathrm{C}$ & 11 & 18 & $\mathbf{0 3}$ & 12 & 59 & 28 & 02 & 17 \\
\hline 36 & $\mathrm{C}$ & 01 & 09 & 04 & 17 & 69 & 36 & 01 & 13 \\
\hline 37 & C & 20 & 22 & 11 & 20 & 35 & 14 & 09 & 19 \\
\hline 38 & $\mathrm{C}$ & 05 & 09 & 13 & 17 & 38 & 16 & 19 & 33 \\
\hline 39 & D & 09 & 13 & 08 & 13 & 02 & 18 & 56 & 31 \\
\hline 40 & C & 05 & 12 & 04 & 23 & 63 & 27 & 03 & 13 \\
\hline
\end{tabular}

In table 10 there are 160 response options comprising of 40 plausible and 120 implausible one. The main purpose of distracter analysis is to distinguish between plausible and implausible options. There are 8 test items 
found to be confusing as maximum subjects select implausible options rather than true one. All most all distracters are mostly selected by subjects of lower group i.e. negative discrimination.

\subsection{Test Reliability}

An instrument is considered reliable if the instrument produces same results every time when use to evaluate identical measurement. A Kuder Richardson formula, KR20 and KR21 for analyzing test items, which is based on item difficulty, was used to analyze internal consistency of the test. The value of KR20 and KR21 range between 0 to 1 . The closer the value to 1 the better the internal consistency.

$$
\rho_{K R 20}=\frac{k}{k-1}\left(1-\frac{\sum_{j=1}^{k} p_{j} q_{j}}{\sigma^{2}}\right)
$$

Where

$\mathbf{K}=$ Number of test items

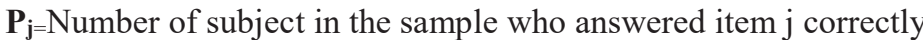

$\mathbf{q}_{\mathbf{j}}=$ Number of subject in the sample who didn't answered item $\mathbf{j}$ correctly

$\boldsymbol{\sigma}^{2=}$ Variance of the total scores of all the subject taking the test

$$
\rho_{\text {RER21 }}=\frac{k}{k-1}\left[1-\frac{\mu(k-\mu)}{k \sigma^{2}}\right]
$$

Where

$\mathbf{K}=$ Number of test items

$\mu=$ Mean score

$\boldsymbol{\sigma}^{2=}$ Variance of the total scores of all the subject taking the test

The value $\mathrm{KR}_{20}=0.7966$ and $\mathrm{KR}_{21}=0.7515$ shows that the test has high reliability.

\subsection{Conclusions and Recommendations}

Results of this study signify the importance of item analysis for constructing a useful, reliable and valid test. Its main focus was to manage item bank for individual discipline during an academic calendar so that a collection of items within acceptable range of difficulty index, discrimination power and suitable distracters obtained. In the present study an achievement test on a unit from subject of physics comprised of 40 test items was prepared and administered to check the level of difficulty, discrimination and standard of distracters. It clearly highlighted the poor, confusing items which need improvement. The findings of the present study clearly highlighted the usefulness of procedure of items analysis for subject teachers to develop quality test items in particular subject area. It is recommended that further studies should be conducted on different topics in physics and in other subjects like biology, chemistry and mathematics.

\section{References}

Best, J. W., \& Kahn, J. V. (2006). Research in education, 10th. New Delhi: PHI Learning Private Ltd.

Boyle, J. D., \& Radocy, R. E. (1987). Measurement and Evaluation of Musical Experiences. MacMillan Publishing Company.

Institute for Interactive Media and Learning (2013). Multiple Choice Questions. Retrieved on 3 February, 2017 from www.iml.uts.edu.au/assessment/types/mcq.

Ebel, R.L. (1972) Essentials of Educational Measurement (1st Edition). New Jersey: Prentice Hall.

Wiersma, W. Jurs. SG (1990). Educational Measurement and Testing (2nd Ed.). Boston: Allyn and Bacon. emailed to Fast track students and RN-BSN students.

Nunnally, JC. 1972. Educational Measurement and Evaluation. 2nd edition. New York. McGraw-Hill.

Ebel, Robert L. Measuring Educational Achievement. Englewood Cliffs, New Jersey, Prentice Hall, 1965.

Brown, Frederick G., "Measuring Classroom Achievement", Halt Richard and Winston, U.S.A.", 1981, pp. 101$110,224 \mathrm{p}$.

Instructional Assessment Resources. (2011). Item Analysis. Retrieved November 9, 2013 from University of Texas at Austin, Instructional Assessment Resources, IAR Web site: http://www.utexas.edu/academic/ctl/assessment/iar/students/report/itemanalysis.php

Ovwigho, B. O. (2014). Empirical Demonstration of Techniques for Computing the

Discrimination Power of a Dichotomous Item Response Test. Journal of Educational and Social Research, 4(1), 189.

Kuder, G. F., \& Richardson, M. W. (1937). The theory of the estimation of test reliability. Psychometrika, 2(3), 151-160. 